\title{
Simultaneous bicompartmental bucket-handle meniscal tears with intact anterior cruciate ligament: a case report
}

\author{
Marios G Lykissas*, George I Mataliotakis, Nikolaos Paschos, Christos Panovrakos, Alexandros E Beris, \\ Christos D Papageorgiou
}

\begin{abstract}
Introduction: Bucket handle tear of the menisci is a common type of lesion resulting from injury to the knee joint. Bucket handle injury of both menisci in almost all cases is associated with a lesion to either the anterior or the posterior cruciate ligament of the knee joint. We describe a case of acute bucket-handle tear of the medial and lateral menisci with intact anterior and posterior cruciate ligaments in a dancer. To the best of our knowledge, there are no previous reports of this type of injury in the literature.
\end{abstract}

Case presentation: A 28-year-old Caucasian Greek woman presented to the emergency department after sustaining an injury to her right knee during dancing. An MRI evaluation demonstrated tears in both menisci of the right knee, while the anterior and posterior cruciate ligaments were found to be intact. A partial medial and lateral meniscectomy was then performed. At a follow-up examination six months after her injury, clinical tests demonstrated that our patient's right knee was stable, had a full range of motion and had no tenderness. She was satisfied with the outcome of the operation and returned to her pre-injury activities.

Conclusion: We present the first case in the literature that describes a combined bucket-handle injury of both the medial and lateral menisci with an intact anterior cruciate ligament. The clinical examination of the anterior cruciate ligament was unremarkable, with no signs of deficiency or rupture. The posterior cruciate ligament was also intact. On magnetic resonance imaging, the ligaments were visualised as intact in all their length. These findings were confirmed by arthroscopic evaluation.

\section{Introduction}

The erect position of the human body requires special structures to support its weight. The menisci have an important role in joint stability and in load transmission across the knee joint $[1,2]$. There are different types of meniscal tears (longitudinal, bucket-handle, horizontal, radial and oblique), and each of them has different characteristics depending on the mechanism of the injury and the location [3].

Bucket-handle tears represent approximately $10 \%$ of all reported cases of meniscal tears [3]. Bucket-handle tears of the medial meniscus are found three times more frequently than bucket-handle tears of the lateral

\footnotetext{
* Correspondence: mariolyk@yahoo.com

Department of Orthopaedic Surgery, University of loannina, School of Medicine, loannina, 45110, Greece
}

(c) 2010 Lykissas et al; licensee BioMed Central Ltd. This is an Open Access article distributed under the terms of the Creative Commons Attribution License (http://creativecommons.org/licenses/by/2.0), which permits unrestricted use, distribution, and reproduction in any medium, provided the original work is properly cited.

\section{Case presentation}

A 28-year-old Caucasian Greek woman presented to the emergency department after sustaining an injury to her right knee during dancing. The mechanism of her injury
compromised vigorous internal rotation of the femur on right knee during dancing. The mechanism of her injury
compromised vigorous internal rotation of the femur on the tibia with the knee in flexion. She complained of mild pain in both the medial and lateral aspects of her knee joint. Her right knee was locked in $35^{\circ}$ of flexion.

meniscus [3]. The presence of this type of tear in both anterior cruciate ligament [4-6]. We describe a case of acute bucket-handle tear of the medial and lateral vious reports in the literature of this kind of injury. ments. To the best of our knowledge, there are no pre-

\section{()}


Physical examination demonstrated negative LachmanNoulis and anterior drawer tests. Clicks or catches were not detected by palpation during flexion, extension, and rotary motions of her knee joint. There was tenderness in her medial and lateral joint line. Results of standard anteroposterior and lateral roentgenograms were normal. A magnetic resonance imaging (MRI) evaluation demonstrated the tears in both menisci of the right knee (Figure 1), while the anterior and posterior cruciate ligaments were found to be intact (Figure 2).

Our patient had no relevant medical history. Her physical examination and laboratory tests were unremarkable. No diseases of the connective tissue or other deficiency of the ligaments were detected.

She underwent a knee arthroscopy in the next 24 hours, and the diagnosis of combined injury of bicompartmental bucket-handle tears with an intact anterior cruciate ligament was confirmed (Figure 3). Arthroscopic evaluation also revealed a discoid lateral meniscus. Moreover, a grade III chondral lesion (graded on the Outerbridge classification), less than $1 \mathrm{~cm}^{2}$ in size, was detected on the medial femoral condyle [7]. A partial medial and lateral meniscectomy was then performed. The decision was made because of the discoid lateral meniscus and the quality of the ruptured part of the medial meniscus. The torn tissue - approximately $40 \%$ of the mediolateral width of each meniscus - was removed. The cartilage defect was repaired by drilling therapeutic holes (approximately 0.5 to $1.0 \mathrm{~mm}$ in diameter) into the subchondral bone marrow space underlying the region of the cartilage lesion (microfracture technique) [8].

At our patient's follow-up examination six months after her injury, clinical tests demonstrated that her right knee was stable, had a full range of motion and had no tenderness. The functional outcome was evaluated using Lysholm scoring. At the time of her presentation to our emergency department she had a Lysholm score of 75, while six months after her injury, her Lysholm score had increased to 85 [9]. She was satisfied with the outcome of the operation and returned to her pre-injury activities.

\section{Discussion}

Bucket-handle is a type of meniscal tear that extends from the posterior horn to the anterior horn when the inner fragment is displaced into the intercondylar notch. Most studies describe bucket-handle tears as comprising approximately $10 \%$ of all meniscal tears. Some authors have reported a higher incidence, with the bucket-handle tear occurring in even $26 \%$ of menisci injuries $[10,11]$. The injury usually occurs in young and middleaged adults, resulting from an acute injury to the knee joint.

Bucket-handle tears are most common among soccer players. It is generally believed that there is no specific
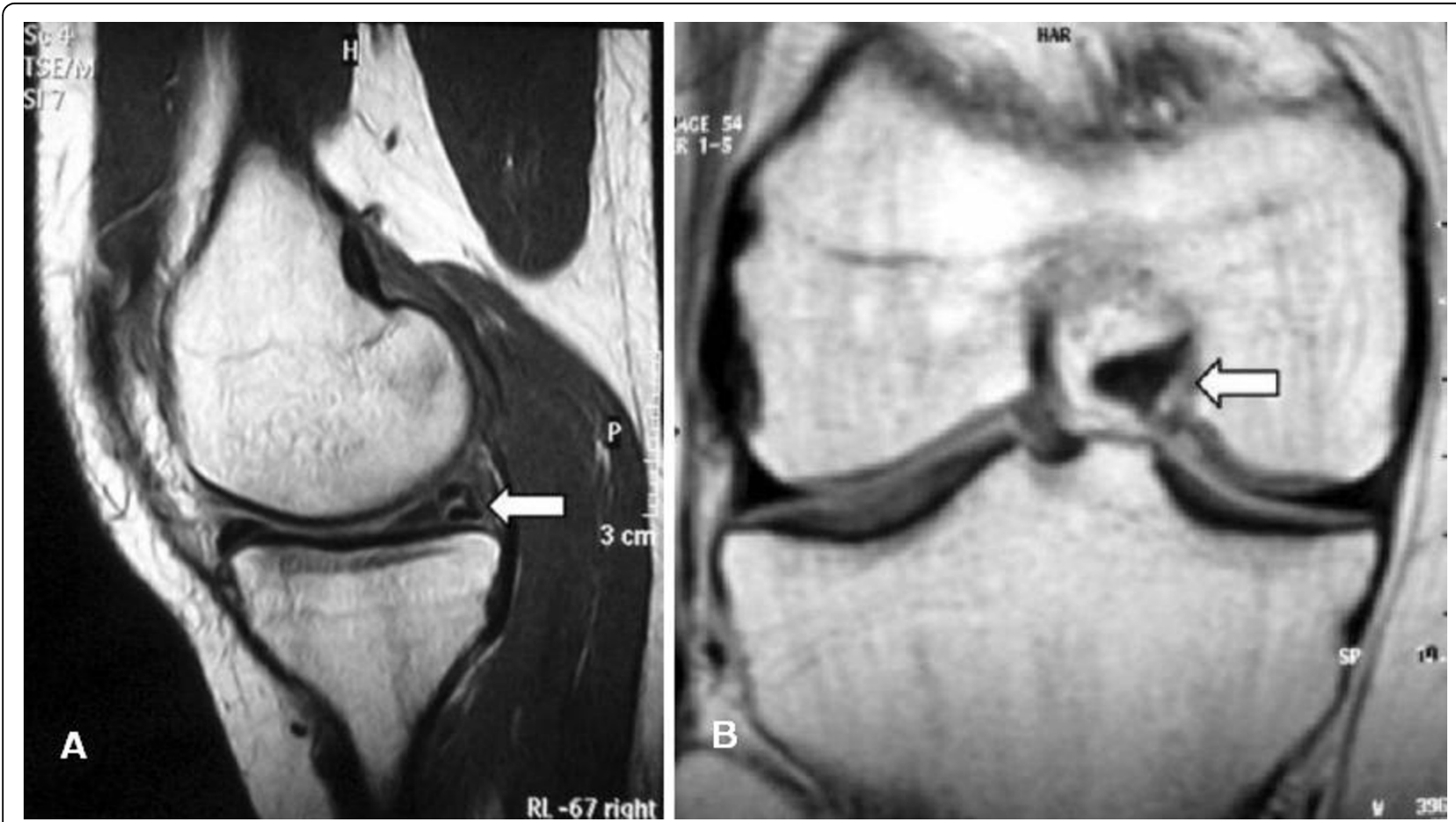

Figure 1 (A) Sagittal and (B) coronal magnetic resonance views revealed tears of both menisci of the right knee (arrows). 


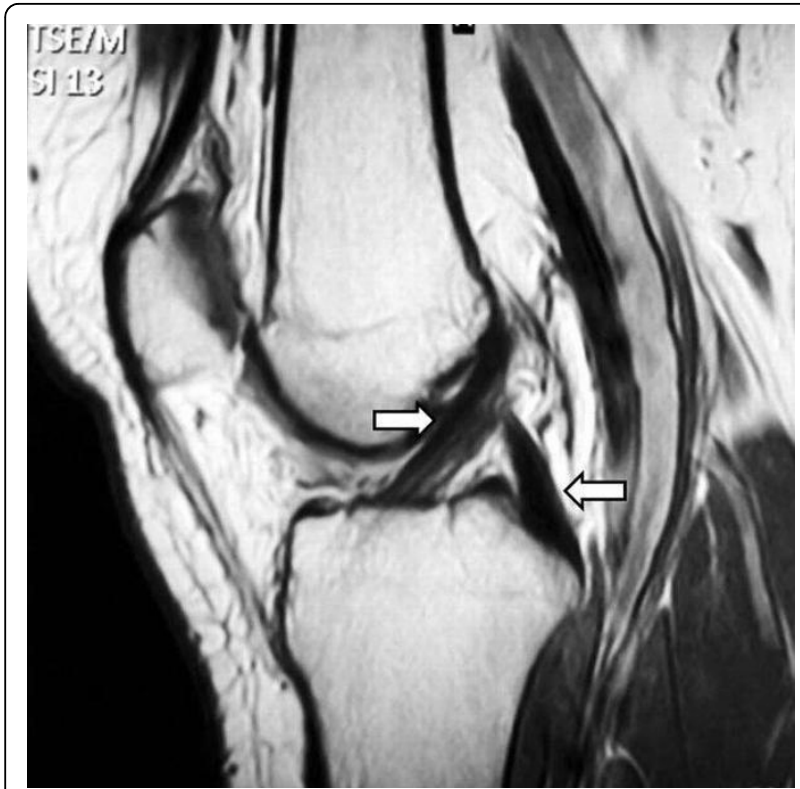

Figure 2 Magnetic resonance imaging evaluation demonstrated normal signal of both anterior and posterior cruciate ligaments (arrows).

mechanism of injury that could lead to this type of meniscal lesion. The fact that there are cases in which bucket handle tears occur without any history of injury to the knee joint, as in our patient, gives rise to theories that bucket-handle tears may be due to degenerative changes in the menisci [3].

Meister et al. suggested that tears in the avascular zone of the medial meniscus that occur in the presence of an intact anterior cruciate ligament may be secondary to a pre-existing, ongoing and underlying disease process [12]. Correlating the arthroscopic image of the torn menisci, the age, the overall level of activity, the medical history and the mechanism of injury in our patient, we conclude that the tear of both the medial and lateral menisci should be considered as the outcome of preexisting and underlying degenerative changes in the menisci, rather than as the result of a specific

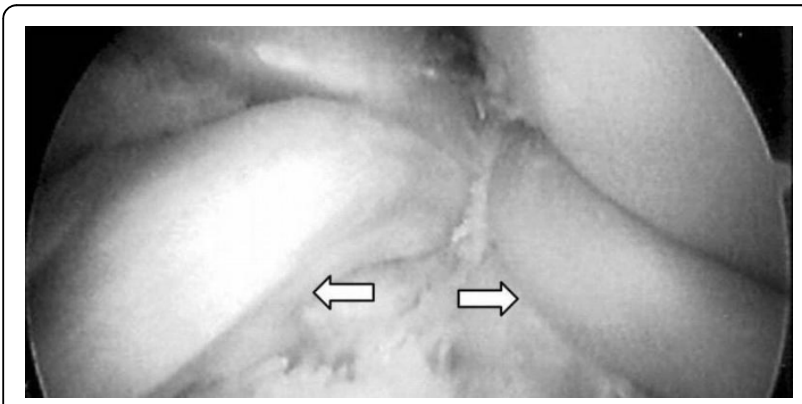

Figure 3 Arthroscopic appearance of bicompartmental buckethandle tears (arrows). mechanism of injury. A previous injury of the knee joint could signal the onset of minor degenerative changes in the meniscus during the healing process. These changes were not significant enough to cause symptoms during the 18-month interval between the two injuries, but they could be a risk factor for the bucket-handle tear in both menisci after the impact of the second injury.

Bucket-handle tears are usually found in the medial meniscus. According to some authors, patients with acute injury of the knee joint and consequent anterior cruciate ligament deficiency are more likely to sustain a bucket-handle tear in the medial meniscus than in the lateral meniscus [13]. The reported incidence of bicompartmental locked bucket handle tear with anterior cruciate ligament injury varies from $7 \%$ to $20 \%[14,15]$. To the best of our knowledge, there are only three cases describing a combined acute injury of both the medial and lateral menisci with concomitant anterior cruciate ligament injury [4-6].

Although the common presenting symptom of a patient with a bucket-handle tear is locking of the knee joint, no history of locking occurred in $20 \%$ of reported cases [3]. Symptomatology may also include pain, poor joint mobility, edema and hematoma. However, these symptoms are not pathognomonic for bucket-handle tears.

The most important diagnostic tool for the confirmation of the clinical suspicion of a bucket-handle tear is MRI. Six different MRI signs have been described in the literature for bucket-handle tears: (i) fragment within the intercondylar notch sign; (ii) absence of the bow tie sign; (iii) disproportional posterior horn sign; (iv) double posterior cruciate ligament sign; (v) double anterior horn sign; and (vi) flipped meniscus sign. The overall sensitivity to MRI of bucket-handle tears range from $45 \%$ to $98 \%$, with some signs having a specificity of $100 \%$. A discoid meniscus which has a thickened body portion, can have the normal bow tie appearance even when a bucket-handle tear is present. In our patient, one of the menisci that sustained a bucket-handle tear was a discoid meniscus.

Thoreux et al. [16] demonstrated that MRI plays an important role in predicting the reparability of a tear. Despite the great contribution of MRI, however, arthroscopy remains the gold standard for the diagnosis, offering at the same time suggestions for treatment.

Because of the importance of the meniscus in load transmission across the knee joint, as well as its unique role in load transmission, many studies suggested the need to preserve the maximum area of the injured meniscus. Recently, Shelbourne and Dickens reported favourable radiographic and subjective results after a long term follow-up of 12 years [17]. Although suturing bucket-handle tears remains a viable option, we 
performed a partial meniscectomy of the affected meniscus in each side.

\section{Conclusion}

Ours is the first case in the literature that describes a combined bucket-handle injury of both the medial and lateral menisci with an intact anterior cruciate ligament. The clinical examination of the anterior cruciate ligament was unremarkable with no signs of deficiency or rupture. The posterior cruciate ligament was also intact. On MRI, the ligaments were visualised as intact in all their length. These findings were confirmed by arthroscopic evaluation.

\section{Consent}

Written informed consent was obtained from the patient for publication of this case report and any accompanying images. A copy of the written consent is available for review by the Editor-in-Chief of this journal.

\section{Authors' contributions}

CDP, MGL, GIM and NP were involved in the patient care, acquisition of data, analysis and interpretation of data, review of literature, and drafting and revising the manuscript. AEB was involved in review of the literature. He also revised the manuscript for important intellectual content. All authors read and approved the final manuscript.

\section{Competing interests}

The authors declare that they have no competing interests.

Received: 4 November 2009

Accepted: 1 February 2010 Published: 1 February 2010

\section{References}

1. Papageorgiou CD, Gil JE, Kanamori A, Fenwick JA, Woo SL, Fu FH: The biomechanical interdependence between the anterior cruciate ligament replacement graft and the medial meniscus. Am J Sports Med 2001, 29:226-231.

2. Allen CR, Wong EK, Livesay GA, Sakane M, Fu FH, Woo SL: Importance of the medial meniscus in the anterior cruciate ligament-deficient knee. $J$ Orthop Res 2000, 18:109-115.

3. Shakespeare DT, Rigby HS: The bucket-handle tear of the meniscus: a clinical and arthrographic study. J Bone Joint Surg Br 1983, 65:383-387.

4. Bugnone AN, Ramnath RR, Davis SB, Sedaros R: The quadruple cruciate sign of simultaneous bicompartmental medial and lateral bucket-handle meniscal tears. Skeletal Radiol 2005, 34:740-744.

5. Cetik O, Cirpar M, Eksioglu F, Uslu M: Simultaneous bucket handle tear of both medial and lateral menisci of a knee with chronic anterior cruciate ligament deficiency. Knee Surg Sports Traumatol Arthrosc 2006, 14:356-359.

6. Tecklenburg K, Schoepf D, Hoser C, Fink C: Anterior cruciate ligament injury with simultaneous locked bucket-handle tears of both medial and lateral meniscus in a 19-year-old female professional ski racer: a case report. Knee Surg Sports Traumatol Arthrosc 2007, 15:1125-1129.

7. Outerbridge RE: The etiology of chondromalacia patellae. $J$ Bone Joint Surg Br 1961, 43:752-757.

8. Beris AE, Lykissas MG, Papageorgiou CD, Georgoulis AD: Advances in articular cartilage repair. Injury 2005, 36(4):S14-23.

9. Lysholm J, Gillquist J: Evaluation of knee ligament surgery results with special emphasis on use of a scoring scale. Am J Sports Med 1982, 10:150-154.

10. Ververidis AN, Verettas DA, Kazakos KJ, Tilkeridis CE, Chatzipapas CN: Meniscal bucket handle tears: a retrospective study of arthroscopy and the relation to MRI. Knee Surg Sports Traumatol Arthrosc 2006, 14:343-349.
11. Wright DH, De Smet AA, Norris M: Bucket-handle tears of the medial and lateral menisci of the knee: value of MR imaging in detecting displaced fragments. AJR Am J Roentgenol 1995, 165:621-625.

12. Meister K, Indelicato PA, Spanier S, Franklin J, Batts J: Histology of the torn meniscus: a comparison of histologic differences in meniscal tissue between tears in $\mathrm{ACL}$ intact and $\mathrm{ACL}$ deficient knees. Am J Sports Med 2004, 32:1479-1483.

13. Baker BE, Peckham AC, Pupparo F, Sanborn JC: Review of meniscal injury and associated sports. Am J Sports Med 1985, 13:1-4.

14. Binfield PM, Maffulli N, King JB: Patterns of meniscal tears associated with anterior cruciate ligament lesions in athletes. Injury 1993, 24:557-561.

15. Tandogan RN, Taşcer O, Kayaalp A, Taşckiran E, Pinar H, Alparslan B, Alturfan A: Analysis of meniscal and chondral lesions accompanying anterior cruciate ligament tears: relationship with age, time from injury, and level of sport. Knee Surg Sports Traumatol ArthrosC 2004, 12:262-270.

16. Thoreux P, Réty F, Nourissat G, Rivière X, Safa P, Durand S, Masquelet AC: Bucket-handle meniscal lesions: magnetic resonance imaging criteria for reparability. Arthroscopy 2006, 22:954-961.

17. Shelbourne KD, Dickens JF: Digital radiographic evaluation of medial joint space narrowing after partial meniscectomy of bucket-handle medial meniscus tears in anterior cruciate ligament-intact knees. Am J Sports Med 2006, 34:1648-1655.

doi:10.1186/1752-1947-4-34

Cite this article as: Lykissas et al: Simultaneous bicompartmental bucket-handle meniscal tears with intact anterior cruciate ligament: a case report. Journal of Medical Case Reports 2010 4:34.

\section{Submit your next manuscript to BioMed Central and take full advantage of:}

- Convenient online submission

- Thorough peer review

- No space constraints or color figure charges

- Immediate publication on acceptance

- Inclusion in PubMed, CAS, Scopus and Google Scholar

- Research which is freely available for redistribution 